\title{
Original Framework for Optimizing Hybrid Energy Supply
}

\author{
Amevi Acakpovi \\ Department of Electrical/Electronics Engineering, Accra Polytechnic, P.O. Box GP561, Accra, Ghana
}

Correspondence should be addressed to Amevi Acakpovi; acakpovia@gmail.com

Received 28 March 2016; Revised 28 May 2016; Accepted 23 June 2016

Academic Editor: Antonio Moreno-Munoz

Copyright (C) 2016 Amevi Acakpovi. This is an open access article distributed under the Creative Commons Attribution License, which permits unrestricted use, distribution, and reproduction in any medium, provided the original work is properly cited.

\begin{abstract}
This paper proposes an original framework for optimizing hybrid energy systems. The recent growth of hybrid energy systems in remote areas across the world added to the increasing cost of renewable energy has triggered the inevitable development of hybrid energy systems. Hybrid energy systems always pose a problem of optimization of cost which has been approached with different perspectives in the recent past. This paper proposes a framework to guide the techniques of optimizing hybrid energy systems in general. The proposed framework comprises four stages including identification of input variables for energy generation, establishment of models of energy generation by individual sources, development of artificial intelligence, and finally summation of selected sources. A case study of a solar, wind, and hydro hybrid system was undertaken with a linear programming approach. Substantial results were obtained with regard to how load requests were constantly satisfied while minimizing the cost of electricity. The developed framework gained its originality from the fact that it has included models of individual sources of energy that even make the optimization problem more complex. This paper also has impacts on the development of policies which will encourage the integration and development of renewable energies.
\end{abstract}

\section{Introduction}

Recent advances in renewable energy have contributed to the increasing deployment of hybrid energy systems as standalone energy systems for providing electricity in remote areas. A hybrid energy system, or hybrid energy, usually consists of two or more renewable energy sources used together to provide increased system efficiency as well as greater balance in energy supply. In other terms, hybrid energy systems are combination of two or more energy conversion devices or two or more fuels for the same device which when integrated overcome limitations that may be inherent in either. Extensive studies have been done to put together different sources of energy in order to design hybrid systems. Moreover, the growing interest for hybrid energy system is being motivated by the identification of a huge deficit of electricity supply in most developing countries.

In Ghana, for instance, based on the Volta River Authority's (VRA) capacity demand and supply balance (20132025), and in line with Ghana's power sector reform and major policy objectives, the country's current total installed generating capacity requires to be increased to $5,175 \mathrm{MW}$ by 2023 in order to address the current power shortages, ensure an adequate supply of electricity, meet the country's forecast growth in demand, and improve the quality of service and reliability of the power system.

The shortage of electricity is a crucial problem faced by populations which hinders development in all directions. Ackwa [1] investigated 350 electricity dependent micro and small enterprises and found out that, according to one-third of the samples, electricity supply was insufficient for their business. It was found that the energy deficit can lower a firm's annual sales by 37-48 percent. Considering that about 90 percent of businesses in Ghana are Medium Scale Enterprises (MSE), providing two-thirds of jobs in Ghana, and that only one in every 10 firms operates a back-up generator, the poor electricity supply can be considered as a major constraint to business operations. Reference [1] revealed that presently, on average, the nation is losing about US\$ 2.2 million per day or US\$ 792 annually, a figure that translates into 2 percent of annual GDP on account of the energy crisis alone. This illustrates the severe impact of electricity shortage on economic development.

One of the most prominent solutions to this problem which is embraced by many countries in our century is the adoption of renewable energy sources to complement 
the existing deficit in electricity supply. However, the cost of electricity attached to some of these renewable sources especially solar and wind is higher compared to the conventional hydro and this therefore consists of a limiting factor. Instead of fully adopting these renewable energies to cater for load request, they are rather used as supportive energy supplies to the main grid to cater for the deficit of energy only. This brings forth the need of combining existing renewable energy supplies in a manner that minimizes the cost of electricity supply.

In this regard, [2] presented a computational model for optimal sizing of Solar-Wind Hybrid Energy System. They performed mathematical modelling of the individual sources involved, solar and wind, and performed hourly measurement of meteorological and load data. In addition, [3-5] equally worked on optimizing hybrid wind and solar systems by also using their self-developed algorithms that do not respond to a general solution for optimization problems. Their approach can be likened to case study approaches for which the limitation is that the solution is mostly not global; that is, it cannot be generalized or exploited to solve similar problems with some variations in the constraints.

Reference [6] investigated the optimization of a PV/Wind integrated hybrid energy system with battery storage under various loads and unit cost of auxiliary energy sources. The main performance measure was the hybrid energy system cost, and the design parameters were PV size, wind turbine rotor swept area, and battery capacity. The system was simulated with ARENA software, commercial simulation software, and was optimized using the OptQuest tool. Likewise, the studies of $[7,8]$ were based on software known as HOMER. The lack of evidence in the exact mathematical approach adopted to solve the optimization problem created an uncertainty on the effectiveness and reliability of the aforementioned software. Furthermore [9] developed a computational optimization technique for hybridising solar, wind, and hydro energy. Artificial intelligence was developed to implement the optimization function and this was executed with Matlab software. The system results were satisfactory in terms of reliable combination of available energy sources that feed a particular load at a minimum cost of electricity.

In addition, a computational framework for efficient analysis and optimization of dynamic hybrid energy system was developed by [10]. Their study dealt with a microgrid system having multiple inputs and multiple outputs (MIMO) which was modelled with the Modelica Language in the Dymola Environment. The optimization functions were, however, implemented with Matlab and other tools. The framework was tested over two optimization problems of which one took operating and capital cost into consideration by imposing linear and nonlinear constraints on the decision variables. Reference [11] proposed a hybrid energy systems modelling and simulation framework that targeted a multiple-input and multiple-output system integrating solar power, wind power, hydropower, and biomass. Their study proposed an energy optimization tool that evaluated the optimization cost and showed optimal mix of energy sources considering cost.

However, one of the major limitations to the literature reviewed is the lack of existence of a general framework that covers all aspects of optimizing hybrid energy sources. Many of the optimizations described above are self-developed methods that do not follow any existing framework or guideline which rigorously enforces some common stages to comply with. Even though $[10,11]$ made an attempt to build such general optimization frameworks for hybrid energy systems, they did not look into the models of hybrid energy system components themselves. They rather resorted to recommending these aspects of the modelling for future studies.

There is a need to fill in the gap identified in order to improve upon hybrid energy system optimization in general. The development of a framework will subsequently guide the implementation of hybrid energy systems in general and provide fair and reliable means of assessing their effectiveness. This paper, therefore, aims at developing a general framework for optimizing hybrid energy systems which encompasses all aspects of the optimization process including the individual modelling of each energy source. The framework will be tested with sample data collected from Accra. The rest of the paper is structured as follows. Section 2 deals with the materials and methods, Section 3 elaborates on the results and discussion, and the last section presents the conclusion and recommendations.

\section{Materials and Methods}

2.1. Development of the Framework. The proposed framework for hybrid energy optimization is depicted in Figure 1. Figure 1 is divided into four parts. The first part consists of the input variables to the renewable energy sources which directly or indirectly determine the energy produced by each source for a period of a month. For instance, wind speed data will help estimate the energy produced by a wind turbine, solar radiation and average temperature will determine the energy generated by a solar module, and water flow and head can also help determine the available energy produced by a hydroelectric power plant.

In the second stage, the unit model of energy generation will transform the available input variables into energy, based on standard analytical models. This stage mainly deals with a mathematical description of how individual models will transform the input variables into energy and involves deep knowledge of theory of energy conversion for each source of energy. The difficulty at this level lies in the fact that analytical models of renewable energy generation are mostly not linear and do involve many differential and integral equations between input and output variables. Therefore, it is sometimes difficult to establish a straightforward relationship between input and output and this leads to the adoption of computer based modelling like Simulink modelling and others.

The third stage consists of the brain of the system, where the artificial intelligence is being implemented. From Figure 1, the artificial intelligence box takes an input from all the energy generated by the individual sources in stage two.

It also has an estimate of cost of electricity per individual sources which is determined based on the knowledge of 


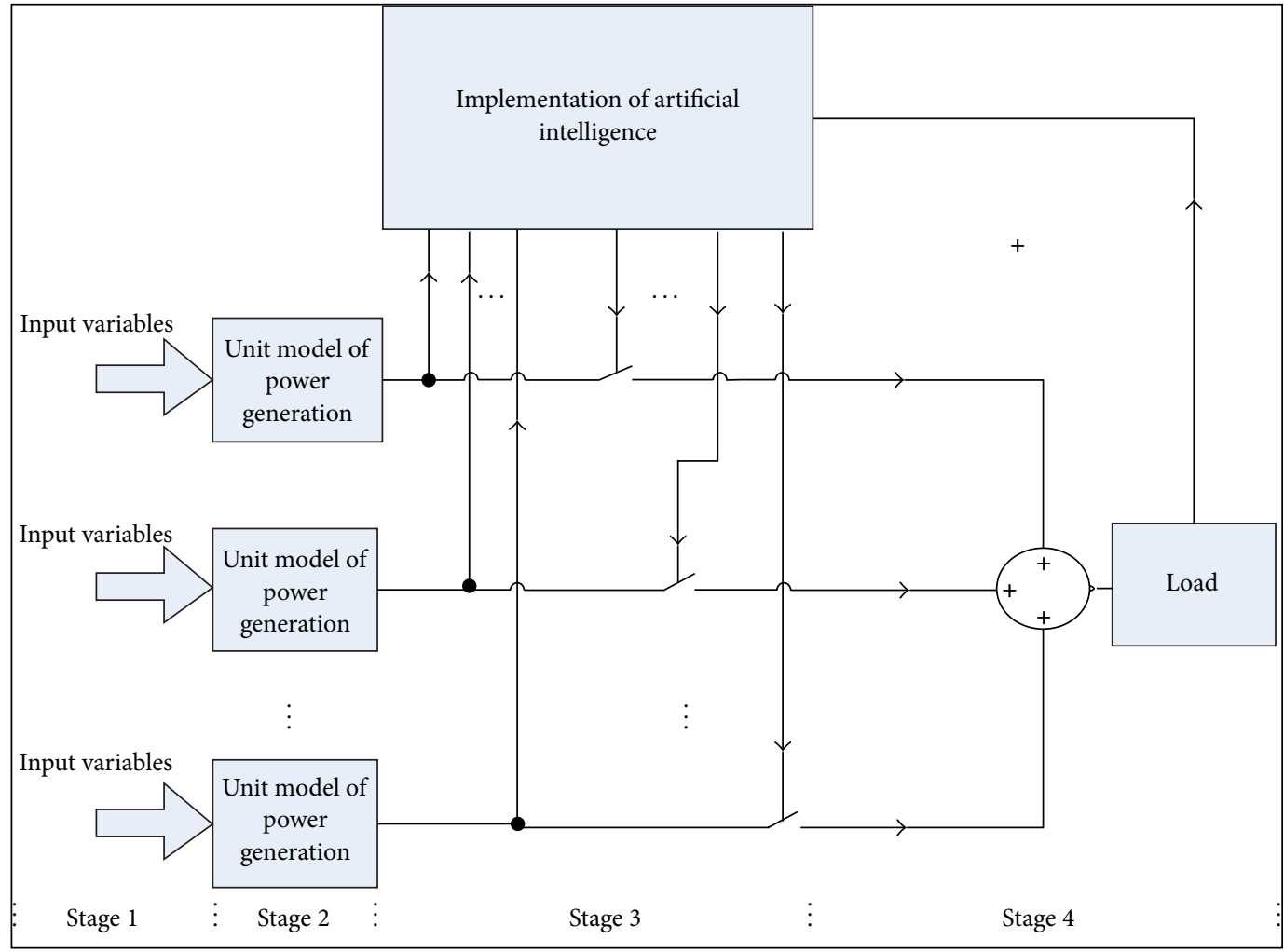

FIGURE 1: Proposed framework for the hybrid energy switching system.

capital cost, capital recovery factor, operation, and maintenance cost. The artificial intelligence box equally monitors the load request and constraints of each variable. It then implements an optimization solution to determine which different sources will be selected to feed the load. The selection is done by a control system applied on the various switches which can be closed or opened to, respectively, select or unselect a particular source of energy generation that will feed the load.

Moreover, the function of the artificial intelligence box is well explained with the flowchart in Figure 2. For a solar, wind, and hydro hybrid energy supply, for instance, the input data to be loaded will consist of wind velocity, solar radiation and temperature, hydro data, and load request. The next step in the flowchart shows that the input energy will be calculated with the unit cost of electricity per each source. The estimated energies with constraints on variables and load satisfactions will be used to solve an optimization problem based on cost, using one method from a set of defined optimization methods. Available optimization solvers include metaheuristic optimization techniques like PSO for nonlinear problems with many inputs. Once the optimization problem is solved, the selected sources and their contribution in terms of energy are derived. This is further used to calculate an average cost of electricity for the hybrid system and the results are saved. The process is repeated for all the available $N$ optimization techniques and the results are finally compared to determine a global best solution which will be implemented.
In the fourth stage, the selected sources are added up together to feed the load and the process is repeated continuously. The paragraph below shows how the cost of electricity is being estimated for a hybrid solar, wind, and hydro hybrid system.

2.2. Estimation of Electricity Cost for a Solar, Wind, and Hydro Hybrid System. Considering a power system made of $N_{\mathrm{s}}$ solar plants, $N_{\mathrm{w}}$ wind power plants and $N_{\mathrm{h}}$ micro-hydrogenerating stations located in the same stream, and referring to $[8,9]$, the total annualized life cycle cost of the system incorporating components of both capital cost and operating cost is given by

$$
C_{\mathrm{an}}=C_{\mathrm{ans}}+C_{\mathrm{anw}}+C_{\mathrm{anh}}
$$

with

$$
\begin{aligned}
& C_{\mathrm{ans}}=C_{\mathrm{cs}} \cdot \mathrm{CRF}_{\mathrm{s}}+C_{\mathrm{os}}, \\
& C_{\mathrm{anw}}=C_{\mathrm{cw}} \cdot \mathrm{CRF}_{\mathrm{w}}+C_{\mathrm{ow}}, \\
& C_{\mathrm{anh}}=C_{\mathrm{ch}} \cdot \mathrm{CRF}_{\mathrm{h}}+C_{\mathrm{oh}},
\end{aligned}
$$

where (i) $C_{\text {ans }}, C_{\text {anw }}$, and $C_{\text {anh }}$ represent, respectively, the annualized life cycle cost of energy for the solar, wind, and hydropower generation, (ii) $C_{\mathrm{cs}}, C_{\mathrm{cw}}$, and $C_{\mathrm{ch}}$ represent, respectively, the capital cost of investment for the solar, wind, and hydropower generation, (iii) $C_{\mathrm{os}}, C_{\mathrm{ow}}$, and $C_{\mathrm{oh}}$ represent, 


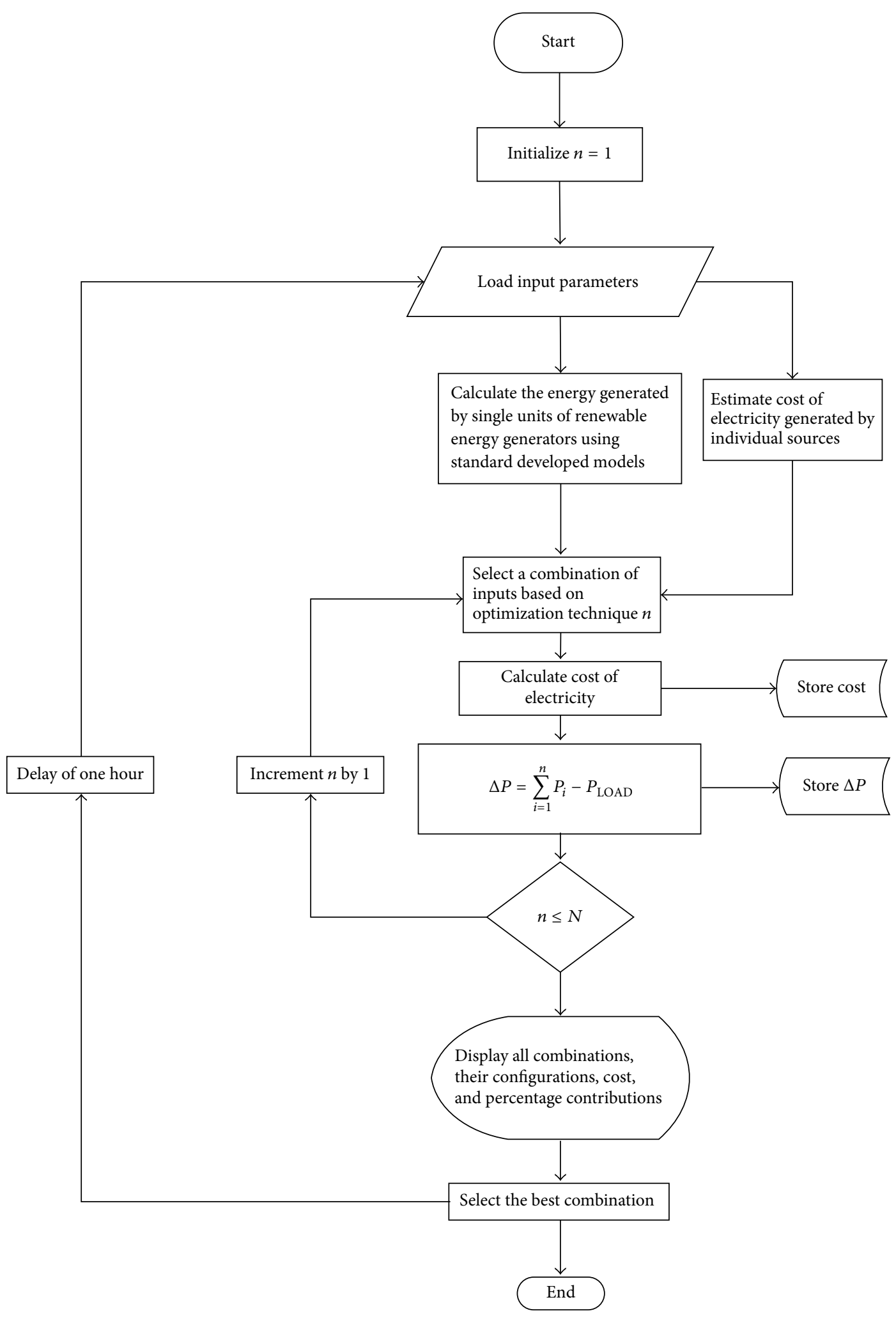

FIGURE 2: Hybrid system optimization framework. 
respectively, the operation and maintenance costs for the solar, wind, and hydropower generation, and (iv) $\mathrm{CRF}_{s}$, $\mathrm{CRF}_{\mathrm{w}}$, and $\mathrm{CRF}_{\mathrm{h}}$ represent, respectively, the capital recovery factor for the solar, wind, and hydropower generation.

The unit costs of electricity $C_{\mathrm{us}}, C_{\mathrm{uw}}$, and $C_{\mathrm{uh}}$, generated, respectively, by the solar, wind, and hydropower plants, can be expressed as follows:

$$
\begin{gathered}
C_{\mathrm{us}}=\frac{C_{\mathrm{ans}}}{E_{\mathrm{s}}}, \\
C_{\mathrm{uw}}=\frac{C_{\mathrm{anw}}}{E_{\mathrm{w}}}, \\
C_{\mathrm{uh}}=\frac{C_{\mathrm{anh}}}{E_{\mathrm{h}}},
\end{gathered}
$$

with $E_{\mathrm{s}}, E_{\mathrm{w}}$, and $E_{\mathrm{h}}$ being the net energy generated by the solar, wind, and hydropower plants, respectively, over a year.

The cost of electricity generated by the hybrid energy system over a period of time $T$ can be expressed as follows:

$$
\begin{aligned}
C_{E}= & C_{\mathrm{us}} \cdot \int_{0}^{T} a_{\mathrm{s}} \cdot P_{\mathrm{s}}(t) d t+C_{\mathrm{uw}} \cdot \int_{0}^{T} a_{\mathrm{w}} \cdot P_{\mathrm{w}}(t) d t \\
& +C_{\mathrm{uh}} \cdot \int_{0}^{T} a_{\mathrm{h}} \cdot P_{\mathrm{h}}(t) d t,
\end{aligned}
$$

where $a_{\mathrm{s}}, a_{\mathrm{w}}$, and $a_{\mathrm{h}}$ represent, respectively, decision variables or coefficients of selection of the plants. $P_{s}(t)$ represents the instantaneous power produced by the solar plant. represents the instantaneous power produced by the wind plant. $P_{\mathrm{h}}(t)$ represents the instantaneous power produced by the hydropower plant.

The power generated by a photovoltaic system depends on two fundamental parameters, namely, the solar irradiation and the ambient temperature, as shown by (5) (Acakpovi and Hagan [10], Villalva et al. [11], Ramos-Paja et al. [12], and Tsai et al. [13]). Consider

$$
P(t)=\mathrm{n} A G(t)
$$

where $\mathrm{y}$ is the PV generation efficiency, $A\left(\mathrm{~m}^{2}\right)$ is the PV generator area, and $G(t)$ is the solar irradiation in tilted module plane $\left(\mathrm{W} / \mathrm{m}^{2}\right)$. follows:

The efficiency $\mathrm{g}$ further relates to the temperature as

$$
\mathrm{y}=\mathrm{y}_{\mathrm{r}}\left[1-\beta\left(T_{\mathrm{c}}-T_{\text {cref }}\right)\right]
$$

$\eta_{\mathrm{r}}$ is the reference module efficiency, $\beta$ is the temperature coefficient, and $T_{\text {cref }}$ is reference cell temperature in degree Celsius. For this study, $T_{\text {cref }}=25^{\circ} \mathrm{C}, \beta=0.05 \% /{ }^{\circ} \mathrm{C}$, and $\eta_{\mathrm{r}}=25 \%$.

The output power of a wind turbine generator system is usually given by (7) as illustrated by Khajuria and Kaur [14], Abbas and Abdulsada [15], and Acakpovi and Hagan [16]:

$$
P_{\mathrm{m}}(t)=\frac{1}{2} \rho_{\mathrm{a}} A C_{\mathrm{p}}(\lambda, \alpha) V_{\mathrm{w}}^{3}(t),
$$

where (i) $C_{p}$ is the coefficient of performance also called power coefficient, (ii) $A$ is the swept area by the turbine's blades $\left(\mathrm{m}^{2}\right)$, (iii) $\rho_{\mathrm{a}}$ is the air density $\left(\mathrm{kg} / \mathrm{m}^{3}\right)$, (iv) $V_{\mathrm{w}}$ is the wind speed (m/s), (v) $\lambda$ is the tip ratio, and (vi) $\alpha$ is the pitch angle.

The tip speed ratio $\lambda$ is defined as the ratio of the angular rotor speed of the wind turbine to the linear wind speed at the tip of the blades [17] and can be expressed as follows:

$$
\lambda=\frac{\omega_{\mathrm{r}} R}{V_{\mathrm{w}}},
$$

where $\omega_{\mathrm{r}}$ is the mechanical angular velocity of the turbine rotor in $\mathrm{rad} / \mathrm{s}$ and $V_{\mathrm{w}}$ is the wind speed in $\mathrm{m} / \mathrm{s}$ and $R$ is the radius of the area swept by the turbine's blades [17]. The rotational speed $n(\mathrm{r} / \mathrm{min})$ and angular velocity $\omega_{\mathrm{r}}$ are related by (9) which is given as follows:

$$
\omega_{\mathrm{r}}=\frac{2 \pi n}{60} .
$$

Based on Khajuria and Kaur [14], for a VSWT, the coefficient $C_{\mathrm{p}}$ is calculated as follows:

$$
\begin{aligned}
& C_{\mathrm{p}}(\lambda, \alpha) \\
& \quad=0.73\left[\frac{151}{\lambda_{i}}-0.58 \alpha-0.002 \alpha^{2.14}-13.2\right] e^{-18.4 / \lambda_{i}},
\end{aligned}
$$

with $\lambda_{i}$ being a coefficient given by (11) as follows:

$$
\lambda_{i}=\frac{1}{1 /(\lambda+0.02 \alpha)-0.03 /\left(\alpha^{3}+1\right)} .
$$

The objective is to design a wind turbine that can produce power between $3 \mathrm{~kW}$ and $5 \mathrm{~kW}$. The following values have been assigned to parameters in the formula of $C_{p}$ to satisfy the objective of generating power between 3 and $5 \mathrm{~kW}$.

$$
\begin{aligned}
& n=100 \mathrm{rpm}, \\
& R=2 \mathrm{~m}, \\
& \alpha=0^{\circ}, \\
& \rho=1.225 \mathrm{~kg} / \mathrm{m}^{3} .
\end{aligned}
$$

The values of the power coefficient have therefore been computed on monthly basis for different wind speed recorded in the year 2013 for the area of Accra. The computed values are shown in Table 1.

The general formula for the determination of mechanical power produced by a hydraulic turbine is shown by Fuchs and Masoum [18] and Hernandez et al. [19] as follows:

$$
P_{\mathrm{h}}=\mathrm{\eta}_{\mathrm{t}} \rho_{\mathrm{w}} g H Q(t),
$$

where $\eta_{t}$ is the efficiency of the turbine (a value of $80 \%$ was assumed in this study), $\rho_{\mathrm{w}}$ is the density of water $\left(1000 \mathrm{~kg} / \mathrm{m}^{3}\right), g$ is the acceleration due to gravity $\left(9.81 \mathrm{~m} / \mathrm{s}^{2}\right)$, $Q$ is the water flow passing through the turbine $\left(\mathrm{m}^{3} / \mathrm{s}\right)$, and $H$ is the effective pressure head of water across the turbine (m). 
TABLE 1: Values of power coefficient for monthly wind speed recorded at Accra in 2013.

\begin{tabular}{|c|c|c|c|c|c|c|c|c|c|c|c|c|}
\hline Month & Jan. & Feb. & Mar. & Apr. & May & Jun. & Jul. & Aug. & Sep. & Oct. & Nov. & Dec. \\
\hline$V_{\mathrm{w}}(\mathrm{m} / \mathrm{s})$ & 2.60 & 2.60 & 2.60 & 2.60 & 2.10 & 2.10 & 4.60 & 5.10 & 5.10 & 2.60 & 4.60 & 2.10 \\
\hline$C_{p}(\lambda, \alpha)$ & 0.34 & 0.34 & 0.34 & 0.34 & 0.27 & 0.27 & 0.44 & 0.45 & 0.45 & 0.34 & 0.44 & 0.27 \\
\hline
\end{tabular}

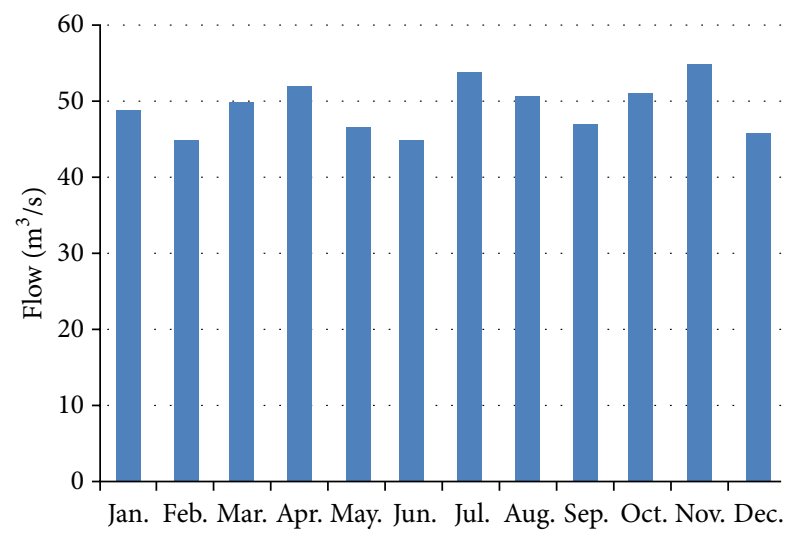

FIGURE 3: Average water flow per month.

Besides, an average water flow of $50 \mathrm{~m}^{3} / \mathrm{s}$ and an average head of $10 \mathrm{~m}$ were assumed with some random variability for different months. The average flow of $50 \mathrm{~m}^{3} / \mathrm{s}$, which is relatively low, was selected with the aim of configuring pico hydro that will generate a maximum power of $4 \mathrm{~kW}$. The randomly distributed profile of water flow is shown in Figure 3.

Replacing the various powers by their expressions, (14) is obtained as follows:

$$
\begin{aligned}
C_{E}= & a_{\mathrm{s}} C_{\mathrm{us}} \int_{0}^{T} \mathrm{j} A G(t) d t \\
& +a_{\mathrm{w}} C_{\mathrm{uw}} \int_{0}^{T} \frac{1}{2} \rho_{a} A C_{\mathrm{p}} V_{\mathrm{w}}^{3}(t) d t \\
& +a_{\mathrm{h}} C_{\mathrm{uh}} \int_{0}^{T} \mathrm{\eta}_{\mathrm{t}} \rho_{\mathrm{w}} g H Q(t) d t .
\end{aligned}
$$

With the assumption that $G(t), V_{\mathrm{w}}(t)$, and $Q(t)$ are all constant over period $T$, the cost function in (14) becomes

$$
\begin{aligned}
C_{E}= & a_{\mathrm{s}} C_{\mathrm{us}} \mathrm{\eta} A G T+a_{\mathrm{w}} C_{\mathrm{uw}} \frac{1}{2} \rho A C_{\mathrm{p}} V_{\mathrm{w}}^{3} T \\
& +a_{\mathrm{h}} C_{u \mathrm{~h}} \mathrm{y}_{\mathrm{t}} \rho g H Q T .
\end{aligned}
$$

The next paragraph proposes an illustration to the optimization problem using a linear programming approach.

2.3. Case Study of a Solar, Wind, and Hydro Hybrid System Using a Linear Optimization Approach. Following formulas (1) to (15), the optimization problem is posed as follows.
Minimize cost of electricity subjected to the following constraints:

(1) The energy generated by the hybrid system should meet the energy demand at any given time as expressed as follows:

$$
a_{\mathrm{s}} \cdot E_{\mathrm{GS}}(t)+a_{\mathrm{w}} \cdot E_{\mathrm{GW}}(t)+a_{\mathrm{h}} \cdot E_{\mathrm{GH}}(t) \geq E_{\mathrm{d}}(t) .
$$

(2) The total energy generated should be within range of minimum and maximum energy that can be generated:

$$
\begin{aligned}
E_{\text {min }} & \leq a_{\mathrm{s}} \cdot E_{\mathrm{GS}}(t)+a_{\mathrm{w}} \cdot E_{\mathrm{GW}}(t)+a_{\mathrm{h}} \cdot E_{\mathrm{GH}}(t) \\
& \leq E_{\text {max }} .
\end{aligned}
$$

(3) Variables should also stay between bounds as follows:

$$
\begin{aligned}
0 & \leq a_{\mathrm{s}} \leq N_{\mathrm{s}}, \\
0 & \leq a_{\mathrm{w}} \leq N_{\mathrm{w}}, \\
0 & \leq a_{\mathrm{h}} \leq N_{\mathrm{h}}, \\
0 & \leq a_{\mathrm{s}}, a_{\mathrm{w}}, a_{\mathrm{h}}, \\
G_{\min } & \leq G \leq G_{\max }, \\
V_{\mathrm{wmin}} & \leq V_{\mathrm{w}} \leq V_{\mathrm{wmax}}, \\
Q_{\min } & \leq Q \leq Q_{\max } .
\end{aligned}
$$

With the assumption that the irradiation $G$, the wind velocity $V_{\mathrm{w}}$, and the water flow $Q$ are all constant during period $T$, the problem can be considered as a linear optimization function subjected to linear inequalities constraints. $E_{\mathrm{GS}}, E_{\mathrm{GW}}$, and $E_{\mathrm{GH}}$ are the output energies, respectively, generated by the solar, wind, and hydropower generators.

The proposed artificial intelligence solves the optimization of the hybrid system using linear programming approach.

2.4. Data Collection for Accra. The data collected for the study consists of the following:

(i) Wind speed and direction.

(ii) Solar radiation.

(iii) Temperature.

(iv) Location parameters including longitude, latitude, and elevation.

(v) Loads variation with time. 
TABLE 2: Data collected from RETScreen software for the area of Accra (2013).

\begin{tabular}{|c|c|c|c|c|c|c|c|c|c|c|c|c|}
\hline Month & Jan. & Feb. & Mar. & Apr. & May & Jun. & Jul. & Aug. & Sep. & Oct. & Nov. & Dec. \\
\hline \multicolumn{13}{|l|}{ Accra } \\
\hline$R_{\mathrm{s}}$ & 4.10 & 4.59 & 5.21 & 5.08 & 5.02 & 3.97 & 3.70 & 3.84 & 4.59 & 5.19 & 4.79 & 3.86 \\
\hline$S_{\mathrm{w}}$ & 2.60 & 2.60 & 2.60 & 2.60 & 2.10 & 2.10 & 4.60 & 5.10 & 5.10 & 2.60 & 4.60 & 2.10 \\
\hline$T$ & 27.4 & 27.8 & 28.0 & 28.1 & 27.9 & 26.6 & 25.0 & 24.6 & 25.1 & 26.2 & 27.2 & 27.3 \\
\hline
\end{tabular}

(i) $R_{\mathrm{s}}$ : solar radiation in $\mathrm{kWh} / \mathrm{m}^{2} /$ day.

(ii) $S_{\mathrm{w}}$ : wind speed in $\mathrm{m} / \mathrm{s}$.

(iii) $\mathrm{T}$ : temperature in ${ }^{\circ} \mathrm{C}$.

TABLE 3: Data collected on electricity bills of a school at Accra (2013).

\begin{tabular}{|c|c|c|c|c|c|c|c|c|c|c|c|c|}
\hline $\begin{array}{l}\text { Month } \\
\text { Energy (kWh) }\end{array}$ & $\begin{array}{l}\text { Jan. } \\
4800\end{array}$ & $\begin{array}{l}\text { Feb. } \\
4100\end{array}$ & $\begin{array}{l}\text { Mar. } \\
4000\end{array}$ & $\begin{array}{l}\text { Apr. } \\
4400\end{array}$ & $\begin{array}{l}\text { May } \\
5000\end{array}$ & $\begin{array}{l}\text { Jun. } \\
4500\end{array}$ & $\begin{array}{l}\text { Jul. } \\
4000\end{array}$ & $\begin{array}{l}\text { Aug. } \\
4100\end{array}$ & $\begin{array}{l}\text { Sep. } \\
4600\end{array}$ & $\begin{array}{l}\text { Oct. } \\
4000\end{array}$ & $\begin{array}{l}\text { Nov. } \\
4200\end{array}$ & $\begin{array}{l}\text { Dec. } \\
4250\end{array}$ \\
\hline
\end{tabular}

Reliable data on wind speed, solar radiation, temperature, and location parameters are provided by the RETScreen Plus software that covers the period from 1997 to 2013. According to [20], the RETScreen Plus is a Windows-based energy management software tool that allows project owners to easily verify the ongoing energy performance of their facilities. It is developed by the Ministry of Energy in Canada in collaboration with NASA. References [21, 22] also describe RETScreen International as an innovative and unique renewable energy awareness, decision support, and capacity building tool developed by CEDRL with the contribution of more than 85 experts from industry, government, and academia. The data collected from RETScreen (2013) for the area of Accra is presented in Table 2.

Load. Data is collected from a tertiary school building located at Accra. The electricity bills issued by the Electricity Company of Ghana (ECG) were used to retrieve the amount of energy consumed every month for the year 2013. The collected data is shown in Table 3 and plotted in Figure 4.

Proposed Linear Programming Approach. Linear optimization problems are mostly solved by graphical means, where all the constraints are plotted separately and the optimal point is determined by means of rigorous observations. With the advent of advanced software such as Matlab, built-in functions have been created to handle linear optimization problem. The most recommended function to solve this problem is the "linprog" function of Matlab which is applied with the following expression:

$$
\left[x_{\mathrm{fval}}\right]=\operatorname{linprog}\left(f, A, b, A_{\mathrm{eq}}, b_{\mathrm{eq}}, \mathrm{lb}, \mathrm{ub}\right)
$$

where the optimized value is kept in the variable fval and the other variables are defined as follows: (i) $f$ is the objective function, (ii) $A$ is a $k$-by- $n$ matrix, where $k$ is the number of inequalities and $n$ is the number of variables, (iii) $b$ is a vector of length $k$, (iv) $A_{\mathrm{eq}}$ is the matrix summarizing all equality constraints, (v) $b_{\text {eq }}$ is a vector of length $m$, (vi) ub is the matrix of upper bounds applied to the variables, and (vii) $\mathrm{lb}$ is the matrix of lower bounds applied to the variables.

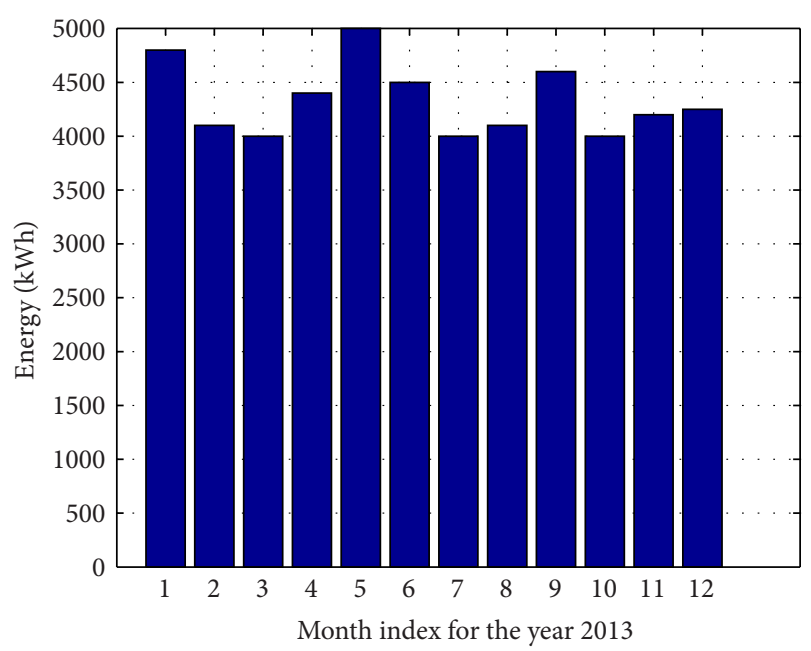

FIGURE 4: Energy consumed by a school complex at Accra for the year 2013.

The solution to our optimization problem is constructed around the "linprog" function of Matlab and can be described by the following algorithm:

(1) Initialize an index variable to $N$ that will serve for iteration and set the period $T$ to one month.

(2) Get the input load data, wind velocity, solar irradiation, and hydro data (water flow and total head) as well as necessary data to evaluate the unit cost of electricity per individual sources.

(3) Calculate the energy generated by individual sources of renewable energy generator using the models described above.

(4) Create decision variables for indexing.

(5) Define lower and upper bounds for all variables.

(6) Define linear equality and linear inequality constraints.

(7) Define the objective function.

(8) Solve the linear optimization problem with the function linprog of Matlab. 


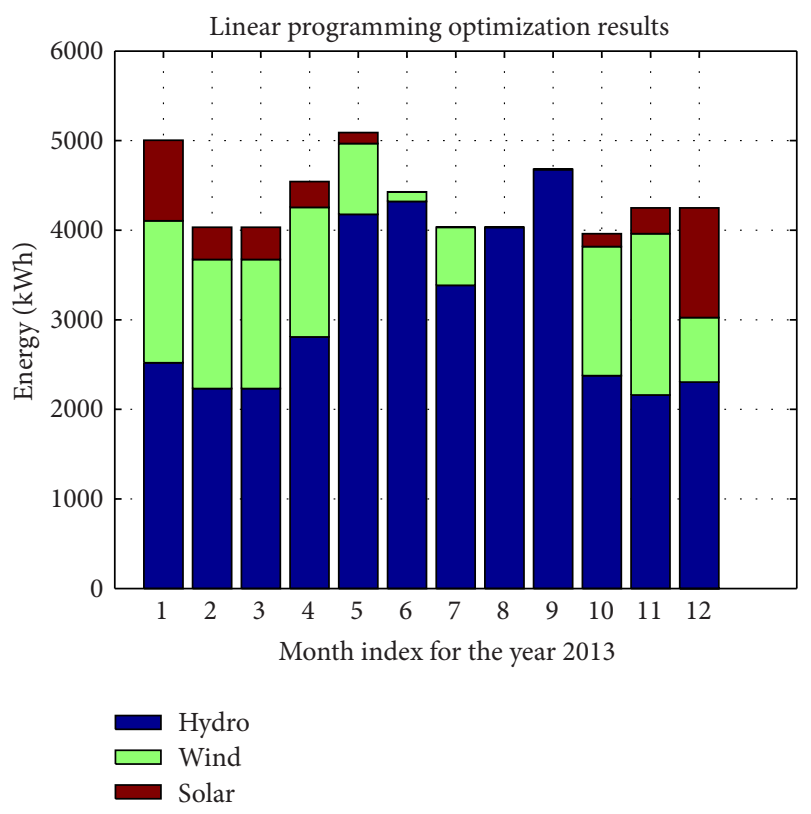

FIGURE 5: Distribution of energy supply based on linear programming approach (case of Accra).

(9) Save result.

(10) Increase the index $N$ by 1 .

(11) If index $N$ is less than or equal to 10 , repeat processes from 2 to 10 .

(12) Display result.

(13) Stop.

\section{Results and Discussion}

3.1. Presentation of Results. The data were fed into the developed Simulink model and simulation results were obtained in terms of graphs. Three basic graphs are plotted comprising the following:

(a) A bar chart shows the dynamic contribution of individual sources in meeting the load. This chart is necessary to prove the dynamism of the developed algorithm as a solution to the proposed optimization problem. Different input conditions must yield different optimization result and this must transpire in the first chart.

(b) The second graph represents the total supplied energy versus the load which also indicates the unmet loads.

(c) The third graph represents the dynamic estimation of the unit cost of electricity over time.

3.2. Interpretation of Results. Figure 5 shows a mix of individual sources to the total energy supplied to the load. It is apparent that the sources of lower cost are used to supply the load, gradually followed by the sources that are more costly. In this case, the hydro is always selected first, followed by the

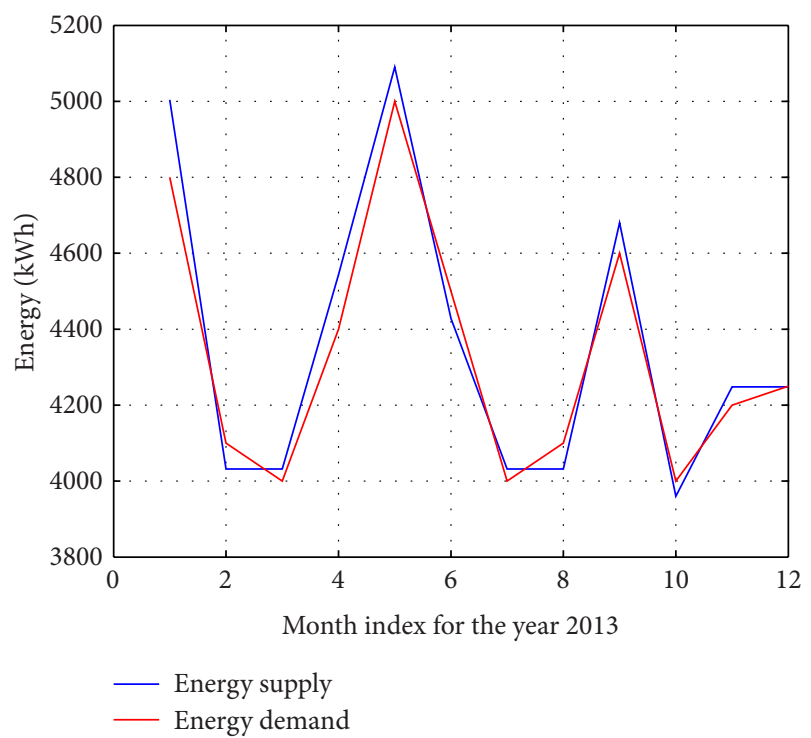

FIGURE 6: Energy supply versus energy demand (case of Accra).

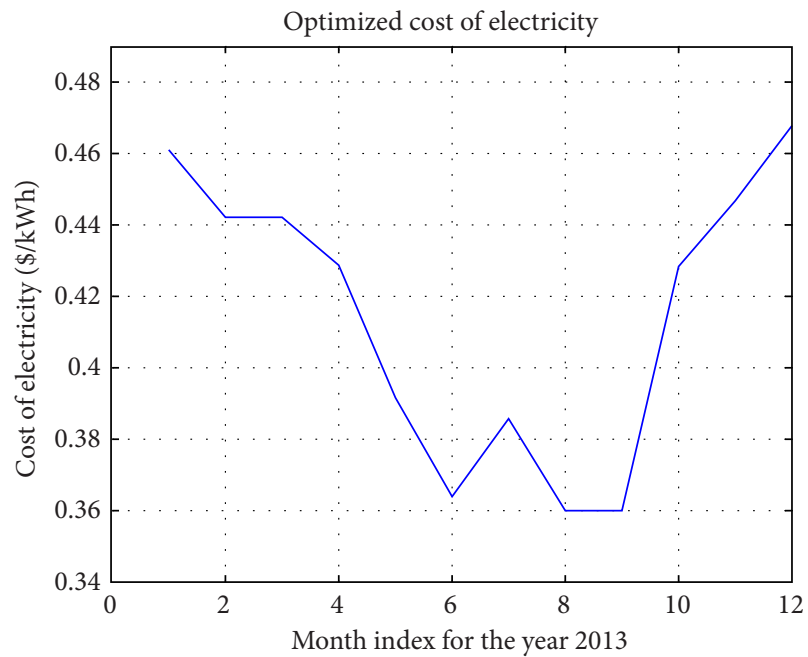

Figure 7: Cost of hybrid electricity (case of Accra).

wind and subsequently by the solar, since this is the highest in cost. On the other hand, the graph on cost of electricity in Figure 7 also shows the same trend. The cost appears to be high at the origin but diminishes after some time and remains low from the sixth month to the ninth month. This pattern is directly correlated to the previous graph on the contribution of individual sources. When the energy is solely supplied by the hydropower plant, the cost is low, but as far as the solar and wind are used the cost of electricity automatically goes higher.

Figure 6, on the other hand, shows the energy demand versus the energy supply. The energy supplied in blue colour is almost always above the demand which is in red with some few exceptions. This explains the reliability of the proposed solution. The few cases, months 2, 6, and 10 precisely, where the required loads were not met, can be attributed to 
the unavailability of enough primary resources needed for energy generation.

3.3. Discussion. A general framework for hybrid energy systems has been developed. This framework encompasses the direct model of individual sources of energy generation at the difference of some previous studies. It further adopts a linear optimization programming approach under Matlab software. The framework was tested with data collected from RETScreen International software for the location of Accra. Results showed interesting dynamics in selecting different sources to supply the load and at the same time obvious minimizing of hybrid energy cost. Also the required energy demands were consistently supplied at the exception of some few cases.

The findings of this study on the proposed framework for HES are congruent with the assertion of Du et al. [17] in the sense that both frameworks propose solution to constrained optimization of hybrid problem taking into consideration the multiple-input and multiple-output aspect. Moreover, the same consideration of capital cost and operation and maintenance cost together with the common use of the Matlab software consists of great factors that confirm the closeness or similarities with the study of Du et al. [17].

Additionally, the findings of [23] corroborate with the proposed framework in this paper which also combines multiple sources of energy with optimization based on cost. Histograms showing mix of energy which satisfies a desired load were equally seen as performance measures for both frameworks.

The proposed framework embeds the models of the hybrid energy components into the framework with the consideration of MIMO system and the use of advanced linear optimization solvers. The involvement of the model of components in the framework is novel and this leads to a significant theoretical contribution. Theoretically, previously developed framework without modelling the HES components should be improved with new models of components. This also encourages the adoption of green energy and improves HES in general.

\section{Conclusion}

A framework for hybrid system optimization has been proposed in this study. The proposed framework considers, in a first stage, input variables that are made of different renewable sources. These sources are fed into their individual energy generation models in stage 2 . The calculated energies for individual sources are then fed to artificial intelligence box which estimates the cost of electricity per individual sources. The artificial intelligence box also monitors the load and decides on the best combination possible to feed the load at the lowest cost. To achieve this, different optimization techniques were proposed in the artificial intelligence box, which were further elaborated in a separate flowchart. The decisions from the artificial intelligence box are implemented through controlled switches that close the link between the selected sources and the load. Stage four of the proposed framework handles the addition of the selected sources before feeding them to the load.

The framework is seen to be novel for the fact that it embeds the modelling of individual sources of energy generation and, therefore, this implies the development of more robust HES with complete models of individual components. New policies and regulatory instruments are encouraged in this regard for the reduction of importation/exportation duties on renewable energy components and also for net metering in Ghana.

Furthermore, it is recommended that optimization of hybrid energy systems should be carried out with more generation plants relying on metaheuristic optimization techniques such as Guaranteed Convergence Particle Swarm Optimization (GCPSO), Hybrid GAPSO (HGAPSO), Combined PSO, and Simulated Annealing Algorithms.

\section{Competing Interests}

The author declares that there are no competing interests.

\section{References}

[1] C. Ackwa, Electricity Insecurity and Its Impact on the Economy of Ghana, Institute of Statistical Social and Economic Research, University of Ghana, Accra, Ghana, 2015.

[2] S. C. Gupta, Y. Kumar, and G. Agnihotri, "Optimal sizing of solar-wind hybrid system," in Proceedings of the IET-UK International Conference on Information and Communication Technology in Electrical Sciences (ICTES '07), pp. 282-287, Tamil Nadu, India, December 2007.

[3] R. Rawat and S. S. Chandel, "Simulation and optimization of solar photovoltaic-wind stand alone hybrid system in hilly terrain of India," International Journal of Renewable Energy Research, vol. 3, no. 3, pp. 595-604, 2013.

[4] P. G. Dalwadi and C. R. Mehta, "Feasibility study of solarwind hybrid power system," International Journal of Emerging Technology and Advanced Engineering, vol. 2, no. 3, 2012.

[5] M. Muralikrishna and V. Lakshminarayana, "A $10 \mathrm{~kW}$ combined hybrid (wind and solar photovoltaic) energy systems for isolated generating system," ARPN Journal of Engineering and Applied Sciences, vol. 6, no. 6, pp. 99-104, 2011.

[6] B. Y. Ekren and O. Ekren, "Simulation based size optimization of a PV/wind hybrid energy conversion system with battery storage under various load and auxiliary energy conditions," Applied Energy, vol. 86, no. 9, pp. 1387-1394, 2009.

[7] D. K. Lal, B. B. Dash, and A. K. Akella, "Optimization of $\mathrm{PV} /$ wind/micro-hydro/diesel hybrid power system in HOMER for the study area," International Journal on Electrical Engineering and Informatics, vol. 3, no. 3, pp. 307-325, 2011.

[8] A. Acakpovi, E. B. Hagan, and M. B. Michael, "Cost benefit analysis of self-optimized hybrid solar-wind-hydro electrical energy supply as compared with HOMER optimization," International Journal of Computer Applications, vol. 114, no. 18, pp. 32-38, 2015.

[9] A. Acakpovi, E. B. Hagan, and M. B. Michael, "Cost benefit analysis of self-optimized hybrid solar-wind-hydro electrical energy supply as compared to HOMER optimization," International Journal of Computer Applications, vol. 114, no. 18, pp. 32-38, 2015. 
[10] A. Acakpovi and E. B. Hagan, "Novel photovoltaic module modeling using Matlab/Simulink," International Journal of Computer Applications, vol. 83, no. 16, pp. 27-32, 2013.

[11] M. G. Villalva, J. R. Gazoli, and E. R. Filho, "Comprehensive approach to modeling and simulation of photovoltaic arrays," IEEE Transactions on Power Electronics, vol. 24, no. 5, pp. 11981208, 2009.

[12] C. A. Ramos-Paja, E. Perez, D. G. Montoya, C. E. Carrejo, A. Simon-Muela, and C. Alonso, Modelling of Full Photovoltaic Systems Applied to Advanced Control Strategies, Universidad Nacional de Columbia, Bogotá, Colombia, 2010.

[13] H. L. Tsai, C. S. Tu, and Y. J. Su, "Development of generalized phottovoltaic model using MATLAB/SIMULINK," in Proceedings on the World Congress on Engineering and Computer Science (WCECS '08), p. 6, 2008.

[14] S. Khajuria and J. Kaur, "Implementation of pitch control of wind turbine using simulink (Matlab)," International Journal of Advanced Research in Computer Engineering and Technology, vol. 1, no. 4, pp. 196-200, 2012.

[15] F. A. R. Abbas and M. A. Abdulsada, "Simulation of windturbine speed control by MATLAB," International Journal of Computer and Electrical Engineering, vol. 2, no. 5, pp. 1793-8163, 2010.

[16] A. Acakpovi and E. B. Hagan, "A wind turbine system model using a Doubly-Fed Induction Generator (DFIG)," International Journal of Computer Applications, vol. 90, no. 15, pp. 6-11, 2014.

[17] W. Du, H. E. Garcia, and C. J. J. Paredis, "An optimization framework for dynamic hybrid energy systems," in Proceedings of the 10th International Modelica Conference, pp. 767-776, Lund, Sweden, March 2014.

[18] E. F. Fuchs and M. A. S. Masoum, Power Conversion of Renewable Energy Systems, Springer, New York, NY, USA, 2011.

[19] G. A. M. Hernandez, S. P. Mansoor, and D. L. Jones, Modelling and Controlling Hydropower Plants, Advances in Industrial Control, Springer, Berlin, Germany, 2013.

[20] R. D. Ganoe, P. W. Stackhouse, and R. J. DeYoung, RETScreen Plus Software Tutorial, NASA Technical Report Servers, 2014.

[21] G. J. Leng, RETScreenTM International: A Standarized Tool for Assessing Potential Renewable Energy Projects, Natural Resources Department of Canada, CANMET Energy Diversification Research Laboratory (CEDRL), 2014.

[22] E. Martinot and O. McDoom, "Promoting energy efficiency and renewable energy: GEF climate change projects and impacts," Pre-Publication Draft, Global Environment Facility, Washington, DC, USA, 1999.

[23] T. R. Ender and C. Haynes, "A hybrid energy systems modelling and simulation framework for regional cooperation through renewable and alternative energy," in Proceedings of the International Conference on Integrating Central Asia into the World Economy, Washington, DC, USA, 2007. 

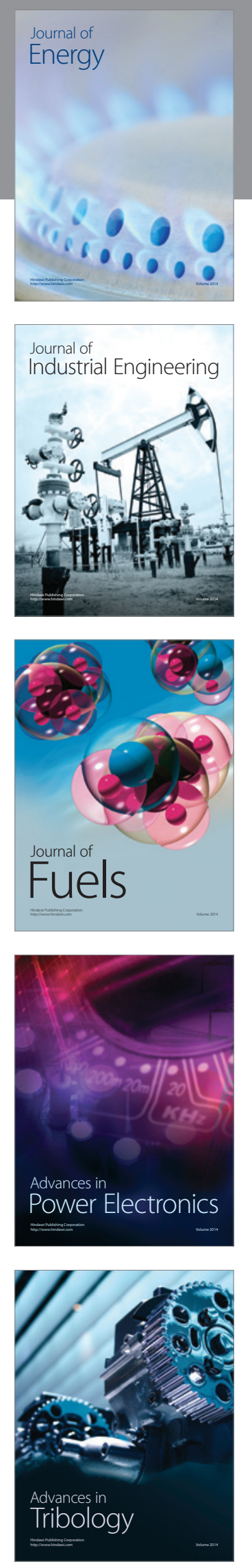
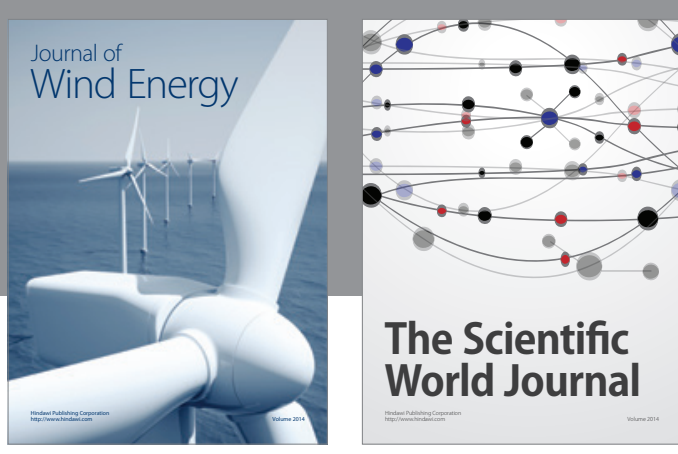

The Scientific World Journal
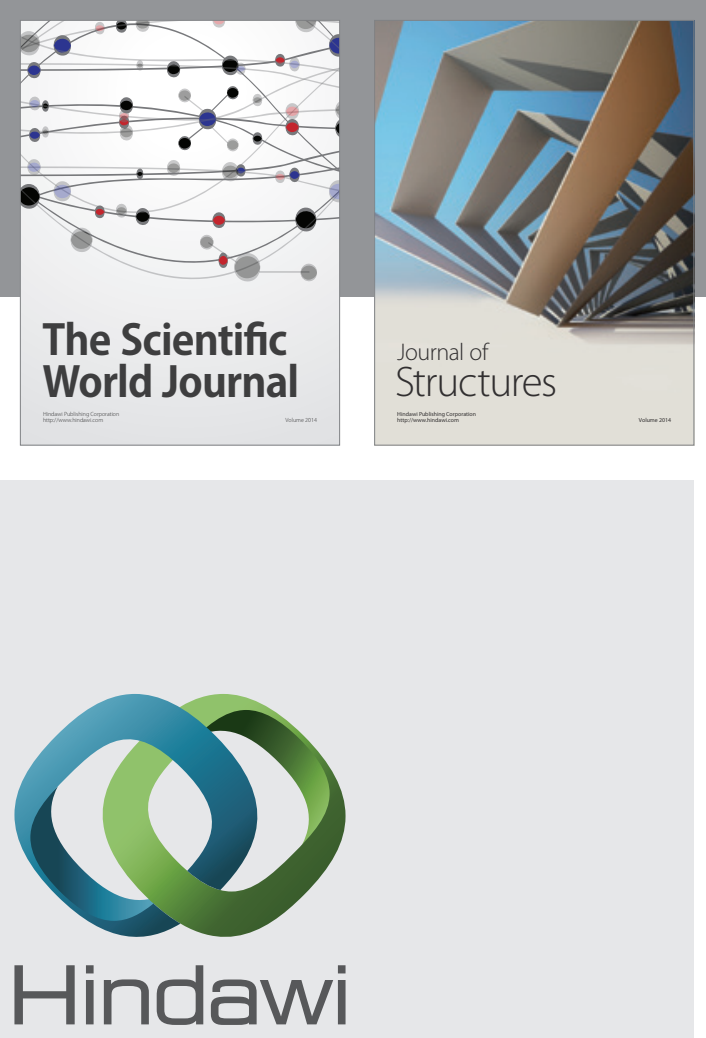

Submit your manuscripts at

http://www.hindawi.com
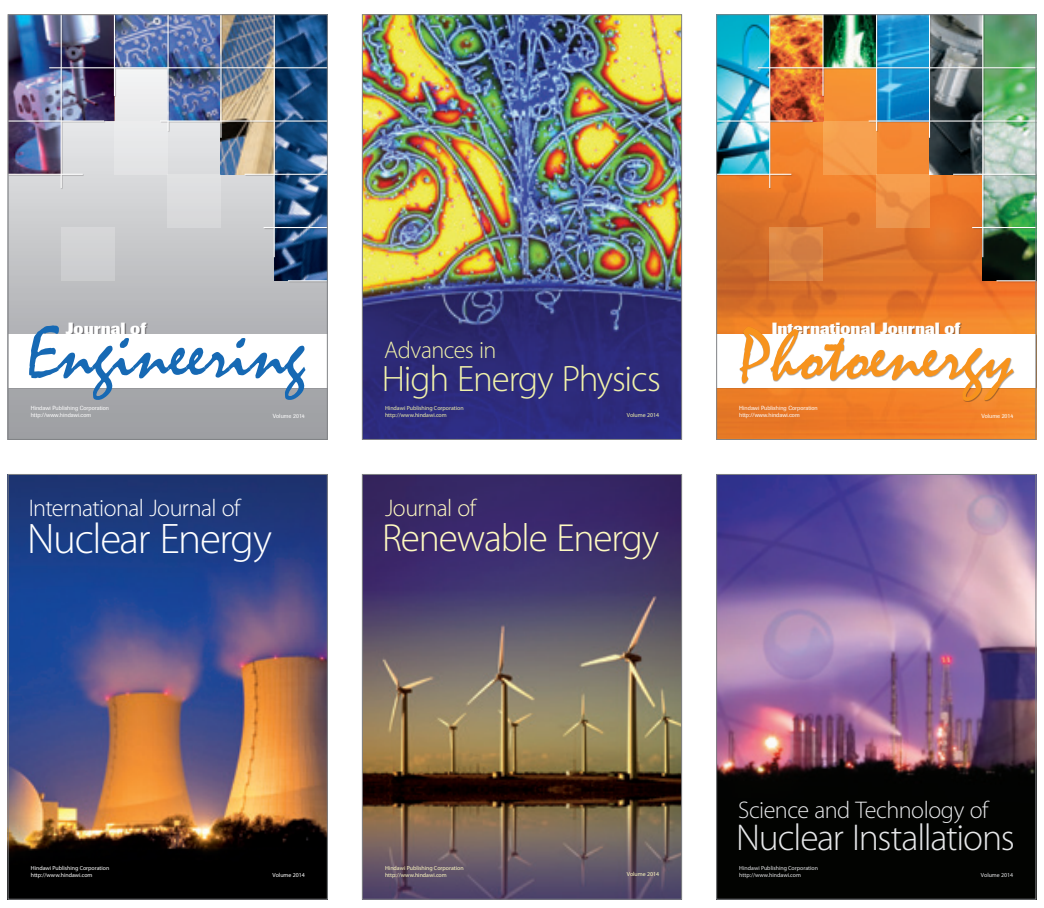
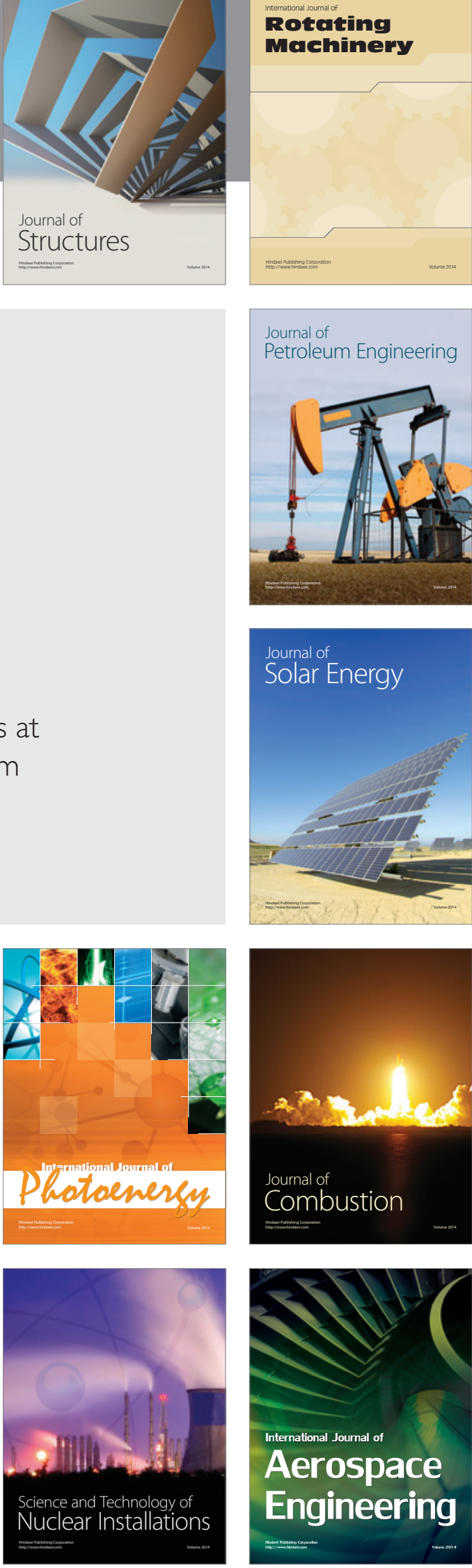